\title{
Opinion \\ Trapping and hunting of migratory raptors in western Georgia
}

\author{
ERWIN VAN MAANEN, IRAKLI GORADZE, ALEXANDER \\ GAVASHELISHVILI and REZO GORADZE
}

\begin{abstract}
Summary
The practice of trapping migratory sparrowhawks Accipiter spp. for falconry and the indiscriminate hunting of other migratory raptors, together with an alleged trade in raptors, were investigated in the eastern Black Sea coastal region of the Republic of Georgia in 1998. Falconry and hunting are deeply rooted in Georgian tradition, exacerbated by the current socioeconomic crisis, and result in significant mortality of migratory raptors during the autumn migration along strategic bottlenecks in the Kolkheti Lowland and along the Atchara-Imereti mountain range. The mortality of migratory raptors resulting directly from hunting and trapping ranges between 1,500 and 3,000 birds during the autumn migration. Education of trappers and hunters through constructive dialogue and advocating best practice is practicable and imperative to reduce the magnitude of raptors killed.
\end{abstract}

\section{Introduction}

Transcaucasia (comprising Georgia, Azerbaijan and Armenia) represents a crucial gateway and stop-over region for migratory birds - including raptors, waterbirds and passerines - undertaking their long and strenuous latitudinal journeys between breeding and wintering grounds. This migratory pathway can be divided into two streams. The primary stream is concentrated on the Georgian Black Sea coast, across an area known as Kolkheti Lowland and all along the Atchara-Imereti mountain range. This stream continues through the Choroki River valley and along the Black Sea coast of north-east Turkey. With respect to volume and species diversity, this stream is believed to surpass other bottlenecks along the northern Mediterranean, notably the straights of Gibraltar, Messina and Bosporus. Further east across inland Georgia the second and more diffuse stream runs in a broad front, or is divided into concentrated lines that are directed by the thermals and updrafts of gorges, ridges, canyons and river valleys of the Greater Caucasus range, Javakheti highlands, the steppes of Iori Plateau, and the Lesser Caucasus range. The eastern route is particularly important for large eagles such as the Steppe Eagle Aquila nipalensis and Imperial Eagle $A$. heliaca, which have been observed to migrate in sizeable groups. Together with eastern Black Sea migrants, inland migrants unite or fly a parallel route beyond the Lesser Caucasus in Turkey, and proceed to their wintering destinations; for 
short-distance migrants in the Mediterranean and Middle East, and for longdistance migrants in sub-Saharan Africa.

In the autumn of 1988 the spectacular raptor migration, the falconry tradition and mortality of migratory raptors resulting from uncontrolled trapping and hunting were investigated in the Georgian Black Sea coastal region. Organized hunting and trapping of migratory birds in countries and cultures of the (sub)Mediterranean is widespread and notorious. An estimated 1,000 million Palearctic birds (including around 100,000 raptors) are believed to perish each year on their migration voyage as a direct or indirect result of these often gruesome traditions (Magnin 1991). Case studies for the Maltese Islands (Magnin 1986, Fenech 1992 and 1997), Cyprus and Turkey (Magnin 1991), the Middle East (Baha El Din and Salama 1991), and recently for Georgia (Abuladze 1994, 1997), provide detailed and differential accounts of magnitude, techniques, sociocultural background, bird mortality and international conservation importance. The primary aim of this study was to extend an investigation by Gerhard Magnin (1989), who characterized raptor migration patterns and the conservation problems associated with the traditional practice of Eurasian Sparrowhawk Accipiter nisus trapping and falconry in north-east Turkey. This paper describes the distinct situation for Georgia.

\section{Study area}

The Kolkheti Lowland encompasses a predominantly flat plain with catchments of relatively unregulated rivers and streams, fed by meltwater from glaciers and snow, frequent rainfall and abundant groundwater springs. The wetland complex of the lowland is composed of shingle seashore, salt and freshwater lakes, marshes, exploited peat bogs and mires, alder-dominated peat-swamp forests, fishponds and wet meadows. Human settlement can be characterized as dishevelled industrial seaside towns and townships. Tranquil villages are scattered between the dense and lush deciduous forests of the foothills. A mosaic of gardens and plantations with exotic plants, cereal crops, eucalyptus forest, tea and citrus predominantly define the cultural and agricultural landscapes. The climate is warm and humid subtropical, with annual precipitation of $2,000 \mathrm{~mm}$, and average temperatures of $6^{\circ} \mathrm{C}$ in January and $23{ }^{\circ} \mathrm{C}$ in July. Apart from its key role as a constituent of the African-Eurasian migratory bird network, the region shelters sizeable and important populations of wintering waterbirds, finches, corvids and raptors (Van Maanen et al. 2000).

\section{Autumn bird migrations}

In the second half of August the start of the autumn bird migration is announced with the penetrating calls of Bee-eaters Merops apiaster. Assorted flocks of raptors descend by gliding from the Greater Caucasus, or sporadically spiral downward and landward from the sea, often driven by the prevailing westerly winds. They converge at lower altitude into the central Kolkheti Lowland and the foothills of the Atchara-Imereti range. It is thought that most raptors on this route traverse the Greater Caucasus through the major 
gorges and river valleys in Svaneti and Ratcha. However, heavy bird migration is also known to occur in the coastal region of Abkhazia (Anonymous 1996, Abuladze 1994, 1996). From the observations in this study it has become evident that the surging migration continues in a southerly direction along the foothills on the western side of the Likhi and Atchara-Imereti ranges, straight past the harbour town of Batumi, and then turning into the Chorokhi River valley. A large stream of raptors shoots through and diverts along the ridges of the mountainous sea coast in north-east Turkey.

The total number of migratory raptors passing through the bottleneck of the Atchara-Imereti range near Batumi in autumn is in the order of tens of thousands. Relative counts differentiating for species, age and gender cohorts throughout autumn and early winter were unfortunately not feasible during this study, but an approximation of the abundance of each species was obtained (Table 1).

Migration of raptors was observed in the foothills near the villages of Likhauri, Makhindjauri and at the border town of Sarpi. Kakhaberi Plain, including the estuary of the Choroki River just south of Batumi, is another important transit area. Here, several raptor species closely pursued the numerous flocks of passerines that dwelt in coastal grasslands around mid-October. For example, many Merlin Falco columbarius roosted on gravel mounds and rocks on the beach, waiting in ambush for larks and pipits.

Eurasian Honey-buzzard Pernis apivorus is the most abundant broad-winged raptor on migration in the region. Two rings recovered from hunters near Batumi provided evidence that part of the migrating Eurasian Honey-buzzard population on the eastern Black Sea route in autumn originates from Finland. The

Table 1. Recorded migratory raptor species and their abundance at Makhindjauri, Georgia, 24 September-27 October 1998.

\begin{tabular}{ll}
\hline Number & Species \\
\hline High (10,000s) & Black Kite Milvus migrans \\
& Eurasian Sparrowhawk Accipiter nisus \\
& Eurasian Honey-buzzard Pernis apivorus \\
Medium (1000s) & Steppe Buzzard Buteo buteo vulpinus \\
& Montagu's Harrier Circus pygargus \\
& Pallid Harrier Circus macrourus \\
& Marsh Harrier Circus aeruginosus \\
& Levant Sparrowhawk Accipiter brevipes \\
& Northern Goshawk Accipiter gentiles \\
& Steppe Eagle Aquila nipalensis \\
& Lesser Spotted Eagle Aquila pomarina \\
& Booted Eagle Hieraaetus pennatus \\
& Short-toed Eagle Circaetus gallicus \\
& Red-footed Falcon Falco vespertinus \\
& Common Kestrel Falco tinnunculus \\
& Hobby Falco subbuteo \\
& Merlin Falco columbarius \\
& Spotted Eagle Aquila clanga \\
Imperial Eagle Aquila heliaca & Osprey Pandion haliaetus \\
Low (10s-100s) & Peregrine Falcon Falco peregrinus \\
\end{tabular}


remaining part is believed to originate from breeding populations in north-east Europe, the Baltic, and from Russia west of the Ural Mountains, together with other migratory raptor species (Magnin 1989).

\section{Trapping of sparrowhawks}

As they descend low into the forested foothills on the coastal side of the AtcharaImereti range, migratory raptors face a great peril. Concealed trappers and hunters wait patiently for them in ambush. This event was closely observed in the foothills near the village of Makhindjauri, $5.5 \mathrm{~km}$ north of Batumi. The trappers are eager to catch Eurasian Sparrowhawks, which they call mimino. During favourable weather they sit in a hut or behind an erect screen, fabricated out of timber and woven branches stuffed with bracken. The trapper starts to build his hides on a place known for high passage of birds, two or three days before the trapping commences. The trapping (chitbadoba) season traditionally starts on 19 August, the Orthodox Day of the Saviour (peritsvaleba), shortly after the first migrant sparrowhawks have passed. The hides are strategically positioned on open ridges between 300 and $400 \mathrm{~m}$ altitude, with a commanding view to the migration front, and often against a background of dense scrubs. Different locations are used to allow for changes in wind direction and position of the sun. Trees are cut and trimmed wherever they obstruct the view. A sail-shaped net (chitbade) is stretched tautly between two bamboo sticks of $2.5 \mathrm{~m}$ in length which are placed firmly upright into the ground directly next to the hide. The net is of knotted black thread with mesh size of $4 \times 4 \mathrm{~cm}^{2}$.

The trappers can be divided into two target groups. First there are professional falconers endeavouring to train a sparrowhawk for the pastime of hunting migrating Common Quail Coturnix coturnix, and to compete in the falconry competitions held at the end of the trapping season. About $25 \%$ of the trapper population can be regarded as professional falconers, belonging to a guild with ethics in falconry and a traditional code of practice. Second, and in a majority are unregistered amateur falconers, who are comparable to thrill-seeking sport fishermen out to maximize their catch. They are keen on trapping extraordinary hawks for show.

The preferred decoy for catching sparrowhawks is a Red-backed Shrike Lanius collurio, locally called ghazho. Catching of decoys in the Guria region conventionally coincides with the religious festival of Elioba, on 3 August. The trap for shrikes consists of a dome-shaped cage, with a trapdoor triggered by a bent wire. A large active insect is used as bait inside the cage, preferably a mole cricket (makhra) shovelled from dung heaps. Both adult and juvenile shrikes are trapped. Juveniles are preferred since adult shrikes are difficult to tame and train. The purpose of the training is to condition the shrike into a conspicuous lure for an unsuspecting sparrowhawk. The shrike is required to flutter explosively or "dance" behind the net. At the trapper's home the tarsi of the shrike are tied with ribbons to a cord of $0.5 \mathrm{~m}$ length. The other end of the cord is tied to the centre of a 1-m-long stick with a roughened and blackened surface. During the first three days the shrike is wild and needs to get accustomed to its perch and the human company. In this period the shrike is only tempted with food. On the fourth day the trapper starts feeding the shrike with minced meat. As soon as 


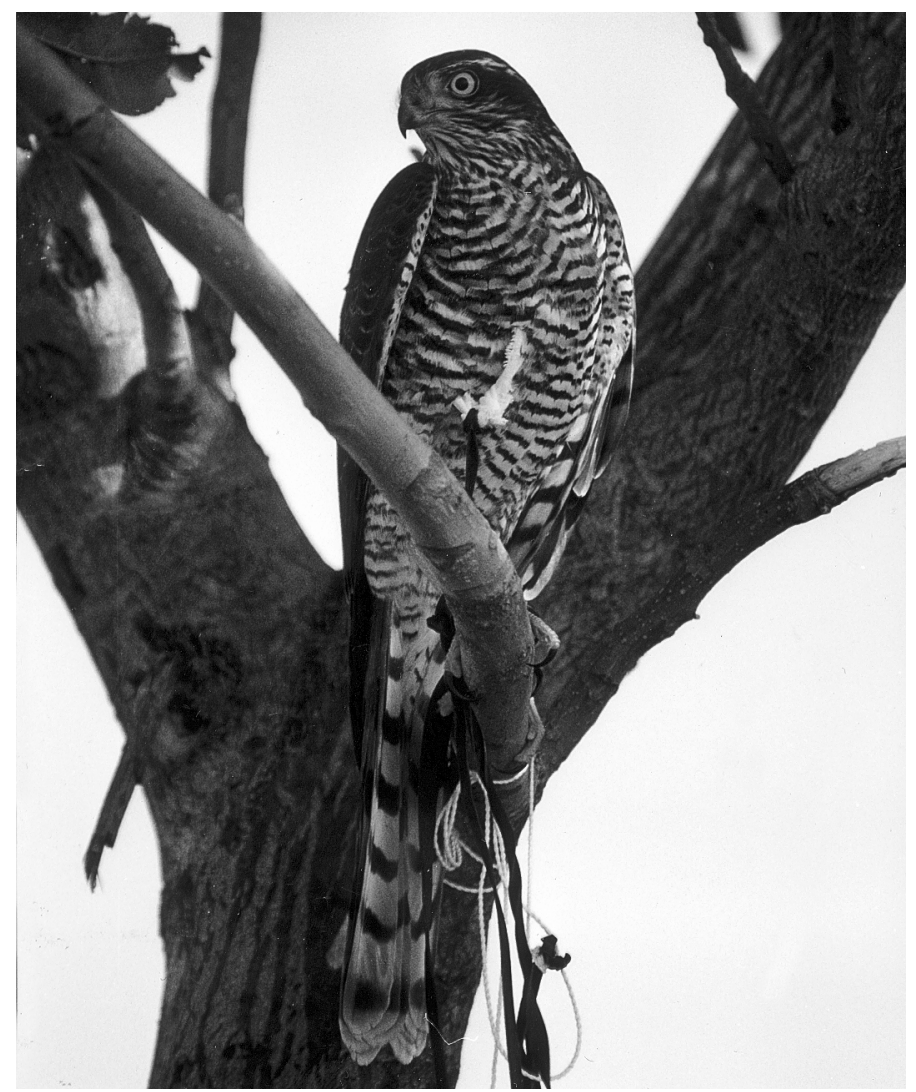

Figure 1. One of many captured Eurasian Sparrowhawks Accipiter nisus. Makhindjauri, September 1998. Photograph by E. van Maanen.

the shrike accepts food from the hand it is tied to the end of the stick and "dance" lessons commence. The shrike is taken outside and the trainer gently rocks the stick at first, increasing it finally to a flick to dislodge the bird and make it flutter upwards. At the same time he should move the stick up and down underneath the fluttering bird to prevent it from quickly resettling. This procedure is repeated twice a day for a period of 10 days, after which the shrike is considered apt for a decoy. Almond-shaped patches of leather or plastic are then positioned with glue to cover the sharp eyes of the shrike. This prevents the shrike from spotting an approaching hawk, which can trigger unwanted escape behaviour. A slot on the underside of the artificial eyelid is left open to allow the shrike to navigate back onto the stick. Throughout the trapping season, the shrike is perched on the same stick, with a small bundle of fresh meat tied on for food. A trapper usually trains two shrikes to allow for a fatigued bird during a long day of trapping, or a decoy dying in action.

From the vantage point of the hides, incoming raptors can be clearly spotted in time for the trapper to move into position. The trapper bobs down behind the hide, peeping out through the slot to monitor the situation. He pushes out the 
stick with the perched shrike, twisting it so that the decoy goes aloft and flutters up and down behind the net, luring an unsuspecting hawk into the trap. When the tempted hawk makes a fast and decisive dive into the net it inevitably becomes entangled. Upon impact the trapper rapidly throws the net forward, flat onto the ground. The captured and often fiercely struggling victim is immediately, but gently removed from the net. Sporadically a hawk gets injured in the net, in which case the trapper kills it and may use it to feed to his shrikes. Undamaged sparrowhawks are tied with a handkerchief (saghliamkhe) around torso and wings, stored in a flannel bag and placed out of harm's way. The number of sparrowhawks trapped at the end of a day can be substantial. One trapper reported a day-catch of 30. It was observed how he managed to catch three birds within 30 minutes. Trapping can therefore become a matter of prestige, with trappers in the same area competing for the highest day-catch. Weather conditions can influence trapping success. On cloudy days sparrowhawks are much more responsive to the temptation of a decoy. The hawks then fly at lower altitude through the foothills, regularly stopping to roost in the vegetation and taking time to scan the environment for prey.

The trapper makes a critical selection of his day-catch, choosing a hawk for falconry or a nice-looking pet. The appraisal is based on morphology, feather markings, colour, behavioural characteristics, age and size. Slender birds are favoured, with a small head, long neck, short tarsi, broad torso, and long wings with "open scissor-like" ends when folded. Feather markings are compared with standard patterns occurring in nature. Yellow, rust and white are the standard colours. Sparrowhawks with unusual white patterns (leucism) in their plumage and an obvious brow stripe are highly desired. Some trappers even go through the trouble of dyeing or bleaching their hawk! Mimino with a "bad character" (i.e. inappropriate for falconry) are discarded. These hawks can be recognized by their "white tongue" and "black eyes" (tval shavi), in fact referring to Levant Sparrowhawk Accipiter brevipes. Good-natured mimino have a "black tongue" and "yellow eyes". The trapper's nomenclature also accounts for age and gender. According to the trappers interviewed, the majority of sparrowhawks trapped are juvenile females, only 10\% consisting of males ("muskets"). A juvenile female sparrowhawk is referred to as nardi and a juvenile musket as gezela. Adult female and male sparrowhawks are respectively referred to as kapo-eti and tawarnaki. Gezela and adult sparrowhawks are rejected, considered unsuitable for training. A nardi is preferred because they are more capable of hunting quail than gezela, and are much more readily trained than adult birds.

Unwanted sparrowhawks are released to continue their migration, killed as food for the shrikes, or presented to friends and relatives. They can be used as toys by children, as models for tourist photography on the seaside boulevard in Batumi, or sold at small fruit and vegetable shops along the roadside.

The number of sparrowhawks caught per trapper each year varies considerably, depending on experience and enthusiasm. One trapper reported a catch of sixty mimino in one autumn. The current President of the Georgian Falconers' Association, Mr Givi Chogovadze, estimates that an average of 25 sparrowhawks are caught seasonally per trapper. The trapping season lasts until mid-October, although in the first week of October some trappers already disassembled their hides and released their shrikes. 


\section{Distribution of sparrowhawk trapping on the Black Sea coast}

Major trapping and falconry activities with sparrowhawks are found along the coast of the Black Sea approximately from the city of Rize in north-eastern Turkey (Magnin 1989) to Batumi in Georgia. From there on the practice can be encountered in Kolkheti Lowland, in the foothills of the Atchara-Imereti range, and all along the coast of Abkhazia. However, in this study it became apparent that in Georgia the trapping tradition is concentrated in and around traditional falconry centres. Towns with a renowned reputation for falconry practice are Gonio, Khelvachauri, Makhindjauri, Kobuleti, Poti, Lanchkuti, Ozurgeti, Chokhatauri, Zugdidi, Senaki, Martvili and Sokhumi (Givi Chogovadze pers. comm.). In many other villages of Kolkheti Lowland the practice was markedly absent.

\section{Training of sparrowhawks for falconry}

Two carefully selected sparrowhawks are used for falconry training. Both birds are trained and the best performer is kept, while untameable hawks are released. Goshawks (kori) are also trapped, but at a much lower frequency than sparrowhawks. They are trained solely for the falconry competitions. At the trainer's home the hawks are perched in or outside of the house on an elevated straight pole, tied with a short leash (khiza) connected to two jesses of string around the tarsi, and an extra supportive ribbon around the breast.

The training (gamartva) of a freshly captured mimino for quail hunting is regarded as an art form, patiently achieved in two stages. The description of the training process below was taken from two rare references (Robakidze 1949, Ghambarasvili 1969) and from interviews with falconers. On the first evening the hawk is taken to a lighted room in the presence of company (people, dogs) to accustom it to the human environment. The bird is held on the hand with a simple glove. The jesses are held taut at equal length between thumb and forefinger to restrain the bird. The trainer makes continuous soft whistling noises to soothe the bird. The trick is to exhaust the bird by depriving it of sleep and food throughout the night. The bird is kept awake by blowing in the ear and by rolling the wrist to displace its footing when it attempts to go to sleep. Preening is regarded as a sign of relaxation. Just before sunrise the hawk is taken for a walk around the cottage. It is then taken to a quiet place and patiently hand-fed with a fresh portion of cleaned and tenderized bird breast muscle or with titbits of egg. Eventually the hawk succumbs to hunger and will start feeding. The falconer can judge the hawk's character by the length of time it takes to relax and start feeding. Stubborn birds are released. The hawk is then placed in isolation on a bowperch (turi) until the next evening. During the second night the above process is repeated, but the portion of food is increased. Over the next few days the hawk is frequently taken out for walks to public and noisy places, for instance inside a water mill. The trainer constantly caresses the hawk on tail and breast, taking care not to stroke the back, which can cause messing of the feathers from oily secretions. After 2-5 days normal feeding usually starts, the sign to proceed to the next stage, which is the hunting of quail.

The hawk is again starved for one day. Upon signs of hunger the hawk is tempted with fresh meat from one hand and required to fly to the other. After 
several successful trials the striking distance is gradually increased. The falconer repeatedly tempts (sakhnieri) the long-leashed hawk to fly longer distances from its perch, showing red meat and blowing a whistle. The next stage is training with live bait, a Quail tied to a line. Quail are readily caught in nets at night or bought at the market during this time. The lure (bavli) is suddenly released before the unsuspecting hawk. The hawk is required to swoop onto the Quail and kill it. After the strike, the falconer quickly dislodges the mantling hawk, to keep it from indulging on its prey. In a strange ritual of reward (datvaltvineba) the trainer dislocates the jaw of the dead Quail and exposes the brain and eyes for the hawk to feed on.

\section{Falconry in Georgia}

Falconry in Georgia is an age-old tradition (Chogovadze 1998), deeply entrenched in culture. According to legend it was in the fifth century AD that King Vakhtang Gorgasali founded the capital of Tblisi, next to the ancient town of Mtskheta. The King chose this site in honour of his favourite falcon, which perished there after striking a pheasant and falling into a hot spring along the Kura River. Archaeological artefacts excavated in Mtskheta indicate that falconry was practised long before this event. During the Middle Ages it flourished in Georgia, while in a similar tradition found in Europe, noblemen developed falconry into a disciplined sport. In the twelfth century, during the reign of King Tamara (actually a woman), Lord Gurieli of Guria appointed a whole family of falconers from Atchara to his court. A head falconer (baziertuhutsesi) supervised the training of high-quality falcons (shevardeni), such as the Peregrine Falcon Falco peregrinus. The family name Bazieri, meaning falconer, can nowadays be found throughout western Georgia. Falcons were deployed from horseback during ritualized hunting parties to catch game birds such as pheasant, which were flushed by drivers banging on drums. Yeoman on the nobleman's feudal estate were only allowed to hunt with a sparrowhawk, for which they annually paid a compulsory tax (sabazarobo) of two chickens. The Ottoman Turks, conquering the western part of Georgia in 1578, greatly appreciated the skills of Georgian falconers. At one stage the Turks demanded a tax for their conciliation, consisting of a dozen virgins, young men, falcons and sparrowhawks. After the Bolshevik revolution in 1917 falconry became taboo in Georgia, as it was associated with aristocracy. Under the restrictions imposed by the Russian Communist regime the tradition nearly disappeared. In the mid-1960s the tradition began to revive, and the sport was finally legalized in 1967 and placed under the auspices of the Falconry Section within the Union of Hunters and Fishermen. Around 500 "professional" falconers, the majority living in western Georgia, are officially registered with this organization. At the beginning of the nineteenth century two styles of falconry were distinguished. These are still known as the Gurian and Lazian styles. The Lazian style is practised by some falconers in the autonomous state of Adjaria and by the Laz people in north-east Turkey. The styles differ in various details. The Gurian falconer traditionally nurtured a juvenile sparrowhawk into adulthood and subsequently hunted with it over many years. Gurian falconers regard their practice as superior to the Lazian style, which employed more primitive methods, such as hunting for quail exclusively with 


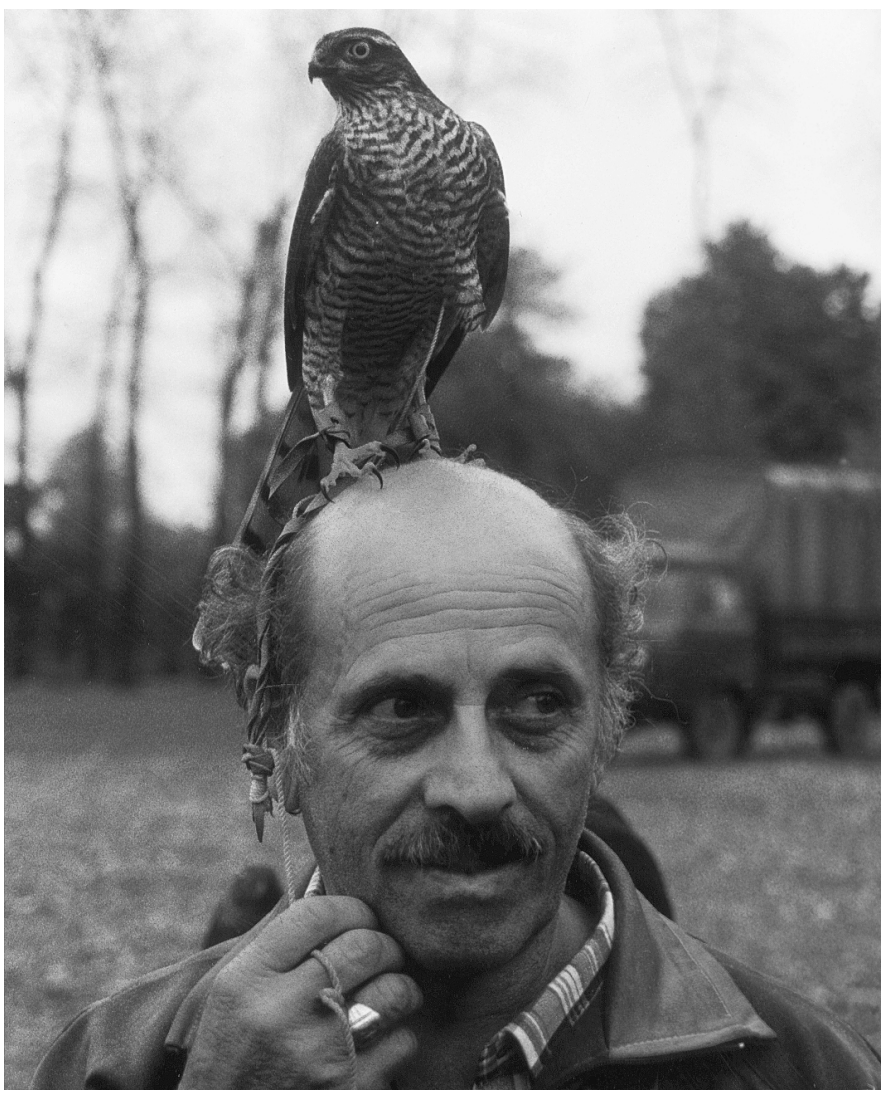

Figure 2. Falconer with his hawk at the falconry competition in Batumi, October 1998. Photograph by E. van Maanen.

juvenile sparrowhawks, which are thrown by hand toward the quarry on a long line, and without using a hunting dog. Today the Gurian style of trapping and training is most widely used in western Georgia. Hence it is also known as the 'Georgian style'. The Lazian style is primarily practised in north-east Turkey.

Sparrowhawks are mainly used for the sport of hunting migrating quail. Salted quail meat is regarded as a delicacy and supplements the staple diet of rural people in winter. The quail-hunting season starts in the second half of September and lasts up to two and a half months. The ready-trained sparrowhawk is dressed with proper leather jesses and with two bells of different tones, one on each ankle. In some cases an extra bell is tied to the breast. Hunting is performed during the cooler parts of the day, usually late afternoon. Calm cloudy days after stormy and rainy weather are regarded as the best opportunity for quail hunting in the coastal area. Beforehand, the hawk is deprived of food to render it fiercely motivated. A falconer usually hunts only in the company of his dog (e.g. Irish or English Setter). Together they hike through the gardens and fields. As soon as his dog points to hidden prey he takes position next to it and raises the hawk in readiness. The dog is then commanded to flush the prey and allow the hawk to accomplish the kill. On its first hunt the hawk is allowed to capture only one 
quail. It is flown from a long line cross-wrapped on the falconer's hand. From the second day onward more quails may be caught, eventually without a line (chapureba). The falconer performs datvaltvineba after each kill, apparently to stimulate the hawk's appetite. With a juvenile sparrowhawk a falconer can catch 5-10 quail per day. Hunting with an experienced adult bird can give much better results of up to 30 quail.

Another aspiration of falconers is to triumph in the local and national falconry competitions, held around the end of October. Falconers assemble at these competitions to proudly display and perform with their hawks. In 1998 the national competition was held on 24 October in Chokhatauri, one of the traditional falconry centres. We counted 41 sparrowhawks, six Northern Goshawks Accipiter gentilis, one Peregrine Falcon and one Merlin entered in this competition. Teams from each falconry centre, comprising the best five falconers from the previously held local competitions, compete against each other. Three generations of falconers can take part during this competition. All of the falconers in Chokhatauri were men, but the competition is also open to women. Traditionally there are three events. The falconer lines up with his hawk at the start of the competition and the jury, according to the nomenclature described earlier, makes a judgement of beauty. However, this event was recently abolished by the Georgian Falconers Association to stop the excessive catching and selection of sparrowhawks for one extraordinary bird. Despite this change in the statutes, many falconers still engage informally in this practice before the start. The authors encountered the display of unusual hawks in Chokhatauri, and excessive trapping by some falconers in the Adjarian foothills. The informal beauty competition is followed by a formal event called sakhnieri, wherein the falconer is required to recall his bird from a distance of 50 meters. Loyalty of the bird to its owner is tested, as well as the response time to the falconer's whistle, flying from perch to hand. In the third and final event the predatory instinct (i.e. fierceness) and hunting skills of the hawk are challenged according to the Gurian style. A quail is released by the referee from a hide or by using a sling, situated $15 \mathrm{~m}$ away from the falconer. The hawk's ability and speed in catching the fleeing quail within the boundaries of the arena is recorded and points awarded. Winners have their names engraved on the challenge cup.

After the competitions and quail-hunting season the hawks should be released. However, a falconer may get attached to his mimino and keep it. Goshawks are rarely kept, because they are too expensive to maintain and there is a lack of typical game (rabbit, pheasant) in western Georgia. In Georgia, particularly in the Guria District, it was traditional to foster a good performing and attractive sparrowhawk for several years. A wintered kapo-eti is considered superior to a freshly trained nardi, with regard to experience, strength and fierceness. According to falconers, game birds larger than a quail can be hunted with a kapo-eti. During winter the hawk is kept perched outside in a cage (dzari) constructed of interwoven branches or in a space inside the house. It is nourished with diverse food such as minced beef, small rodents, birds and fish, and water supplemented with iron. In August, shortly after the moult is complete, the hawk is again trained for the next hunting season. A sparrowhawk may be kept for 5-6 years, but after the fourth year it is 
regarded unfit for hunting, upon which it is usually put down. In Batumi one falconer kept a sparrowhawk for over seven years.

\section{Mortality of sparrowhawks}

Injury and mortality of sparrowhawks as a result of trapping and falconry can be distinguished as follows:

Stress from capture and handling, and heat exhaustion from the method of storage can lead to fatality. Depending on the trapper's attitude, adult female sparrowhawks and muskets that survive are released, presented to others, or killed to feed the shrikes. Injured hawks are always killed. Many dead sparrowhawks were found in the immediate vicinity of trapper's hides, mostly adult females.

Stress, physical mistreatment, malnutrition and infectious disease can take their toll during captivity. Falconers reported a disease, medically known as oropharyngeal trichomoniasis, which kills the bird after repeated secretions of a yellow substance from the crop (see also Magnin 1989). Other conditions and diseases are also reported, notably paralysis of the wings after intense hunting, inflammation or gangrene of the tarsi (a condition known as bumblefoot), and a fatal disease transferred by poultry, most likely avian tuberculosis.

Many sparrowhawks are injured or die during falconry competitions and hunting, mostly through collision, entanglement or hostility from other hawks. The Lazian technique, requiring the hawk to be thrown like a spear onto flushed prey, can inflict serious wing injury.

After their release the hawks are again at the mercy of nature and people. The falconer's hawks allegedly lose their migratory urge (Magnin 1989) and go astray in the region, where chances of survival are reduced in winter when food is scarce and competition for prey with resident and wintering raptors intensifies. Extreme weather conditions in the mountains of north-east Turkey during late autumn are likely to affect sparrowhawks that do continue their journey south. However, the lowlands of Kolkheti are more hospitable during winter and many sparrowhawks probably linger and survive there, preying on the flocks of finches until spring. Many sparrowhawks were observed throughout winter along the Georgian coast and in the lowland areas.

In this study we have refrained from presenting an educated guess of the total annual mortality of trapped sparrowhawks in western Georgia, as there are too many uncertain factors and unknown details to allow a realistic assessment. Magnin (1989) extrapolated a total annual mortality of 10,000 sparrowhawks due to falconry for north-east Turkey, but the relative mortality in Georgia is believed to be considerably less than that, although still significant and reason enough for concern. One must also take into account the fact that trapping in Georgia is neither evenly distributed (occurring only in distinct and traditional places) nor practised with equal intensity in each place. More surveys and interviews with trappers in the different falconry centres are required to clarify this issue. An 
Table 2. Total number of raptors ( 14 species) found killed by trappers and hunters in a radius of 50 $\mathrm{m}$ around each of 12 trapper hides examined in the foothills of Makhindjauri, $5.5 \mathrm{~km}$ north of Batumi, Georgia, September 24-27 October 1998.

\begin{tabular}{lc}
\hline Species & Number of casualties \\
\hline Black Kite Milvus migrans & 1 \\
Montagu's Harrier Circus pygargus & 6 \\
Pallid Harrier Circus macrourus & 4 \\
Marsh Harrier Circus aeruginosus & 5 \\
Eurasian Sparrowhawk Accipiter nisus & 21 \\
Levant Sparrowhawk Accipiter brevipes & 6 \\
Eurasian Honey-buzzard Pernis apivorus & 45 \\
Steppe Buzzard Buteo buteo vulpinus & 26 \\
Steppe Eagle Aquila nipalensis & 1 \\
Booted Eagle Hieraaetus pennatus & 1 \\
Short-toed Eagle Circaetus gallicus & 2 \\
Red-footed Falcon Falco vespertinus & 1 \\
Common Kestrel Falco tinnunculus & 11 \\
Hobby Falco subbuteo & 1 \\
Total & \multicolumn{2}{|c}{131} \\
\hline
\end{tabular}

estimate of raptors dying directly from trapping and hunting around the falconry centres is more realistic (see below).

\section{Mortality of other raptors}

Other raptor species are killed in great numbers, through trapping and shooting (Table 2). The morbid evidence of raptor killing around each of 12 trappers' hides examined in the Makhindjauri area was astonishing. Dismembered remains (torn wings, legs, tails and heads) of raptors were found inside hides and scattered around the immediate vicinity on slippery hunting trails and in dense bushes.

Trappers were interviewed about the reason for the great number of dead raptors around their hides, but the answers were mostly vague and ambiguous. A few trappers confessed that raptors other than sparrowhawks are frequently trapped. There was much confusion about the species involved, with trappers applying their own local nomenclature for species. Typical bird-catching hawks such as falcons and the smaller harriers are frequent by-catch. Common Kestrel Falco tinnunculus, Hobby F. subbuteo and Merlin are occasionally kept as unusual species and taken to the falconry competitions. One trapper reported catching a total of 1o Levant Sparrowhawks (black-eyed or levan mimino) during the season. These are regarded as useless for the hunting of birds. Although many of the trappers interviewed claim to release these uncommon hawks, the authors found substantial evidence that they are deliberately killed. The remains of many Levant Sparrowhawks, all female, were found in the trapping area and around the trappers' cottages, supposedly killed to feed the shrikes. All of the falconers interviewed denied that they fed their sparrowhawks or goshawks with the flesh of other raptors, which they regard as improper. No falconers were actually observed to feed their hawks with raptor flesh.

The sport of hunting migratory birds with double-barrelled shotguns is a pop- 


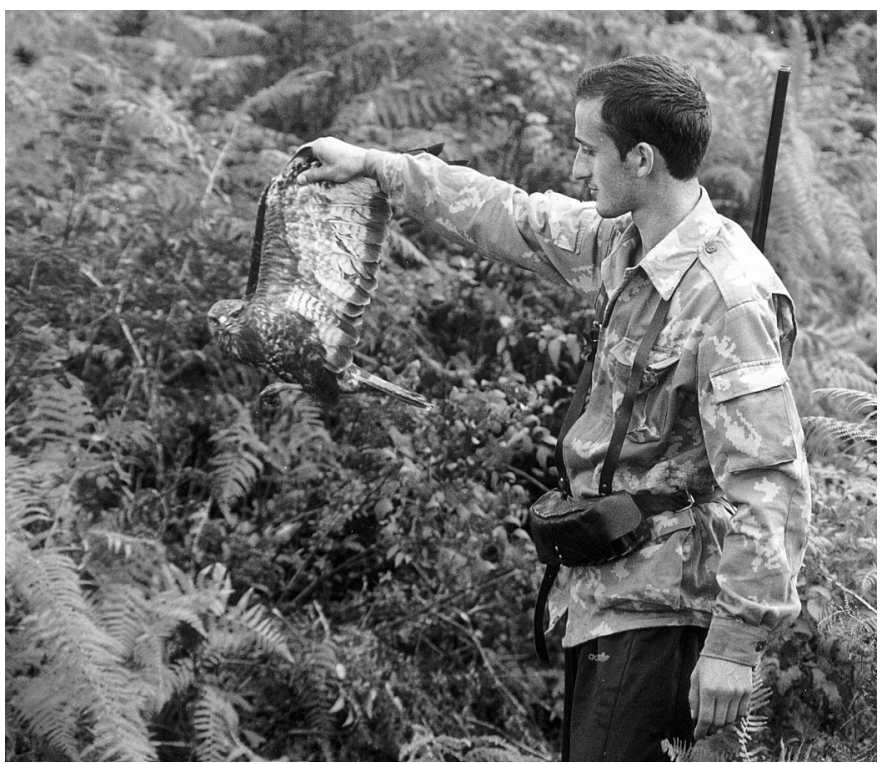

Figure 3. Hunter with shot Steppe Buzzard Buteo b. vulpinus. Makhindjauri, September 1998. Photograph by E. van Maanen.

ular pastime and widespread throughout the Adjarian foothills, Kolkheti Lowland, and on the Kakhaberi plain. It is performed mainly for pleasure and to obtain game birds for consumption. Taxidermy of birds is very rare in Georgia. In Makhindjauri trappers and hunters were found side by side, or to be one and the same with a ready shotgun inside the hide for an opportunistic kill. The hunting season starts in mid-August and continues far into winter, with successive switching of targets as waves of different migratory and wintering species pass through. Hunting is also practised during the spring migration, although with less intensity. The hunters shoot indiscriminately at all birds, day or night. Weather conditions are a great influence on the success rate of killing. Fog and low clouds that frequent the hills make the incoming birds linger and fly low within accurate reach of the guns.

The majority of raptors shot are Eurasian Honey-buzzards. The roads leading down from the hunting grounds to the villages in the foothills around Batumi were littered with the plucked feathers and torn wings of these birds. Flight observations and forensic analysis of feather remains indicated that a front of adult Eurasian Honey-buzzards passes from mid-August till late September. A second wave of juvenile honey-buzzards follows, from mid-September, ending abruptly in mid-October. Eurasian Honey-buzzard is known locally as Jajia or Irao. The official Georgian name is Krazana-chamia Artsivi, literally meaning "Gadfly-eating Eagle". The locals regard this raptor as a true game bird, particularly in the Guria region. It is consumed as a delicacy and sold at markets as "wild hen". The extracted fat is used as an ointment for the skin and claimed to be a remedy for arthritic disorders and asthma.

Although the hunters are supposed to be economical with the expensive home-made or purchased lead-shot cartridges, our observations revealed that 
they are not fussy in choosing their targets. In Makhindjauri migratory birds other than raptors were also found shot, including Golden Oriole Oriolus oriolus, Roller Coracias garrulus, Bee-eater and European Nightjar Caprimulgus europaeus. Woodcock Scolopax rusticola became the primary target of night shooting when the raptor migrations ended in early November. Moreover, attempts to down a Black Stork Ciconia nigra, Common Crane Grus grus and Imperial Eagle were observed. The hunters are indifferent to the fact that they are killing birds of conservation importance, simply because they do not comprehend what is at stake. Onlooking boys are in turn indoctrinated in this abominable practice.

According to our study the number of raptors dying directly from trapping and hunting during the autumn migrations in western Georgia ranges between 1,500 and 3,000 birds annually. This conservative estimate is based on: the number of hunting and trapping spots around known traditional falconry centres (totalling 12); the visible mortality of raptors around trappers' hides in the Makhindjauri area, taken as an average tally; assuming equal intensity and impact of trapping and hunting around each falconry centre. The actual mortality within this range depends on trapping and hunting success, which in turn is strongly dependent on the prevailing weather conditions during autumn.

\section{Evidence for raptor trade in western Georgia}

During this investigation particular attention was paid to any evidence of an alleged trade in raptors from western Georgia. It is undoubtedly true that Peregrine Falcons are occasionally trapped (see also Magnin 1989). One trapper interviewed in Makhindjauri reported the capture of what he termed a "Caucasian Falcon" - the Georgian falconer's jargon for Peregrine Falcon - during this season. According to the trapper's yarn this is a rare event, occurring "once in every 120 years". The falcon was apparently sold for a very high price to a Turkish trader. Another falconer caught a Peregrine Falcon the year before, which escaped. There are rumours of a Turkish middleman in Batumi, purchasing sparrowhawks and falcons for subsequent sale in Turkey. Every year Turks visit Georgian falconers before the trapping season and offer "petty cash" (up to US\$50) in advance for a special hawk. Therefore, it cannot be ruled out that some trade in raptors to the Middle East and Europe is mediated by individuals in Turkey. Furthermore, foreigners occasionally venture to the competitions to check the availability of special birds. During the national competition in Chokhatauri only one falconer with a Peregrine Falcon was encountered on the sidelines, the bird was in appalling condition, suffering from wingtip oedema and an overgrown bill. A handful of falconers in eastern Georgia occasionally take chicks from the eyries of Peregrine Falcon and Saker Falcon Falco cherrug, to raise for their personal pleasure. The statutes of the Georgian Falconers' Association actually prohibit the use of Peregrine Falcons or other red-listed raptors.

\section{Protection of migratory birds in Georgia}

A Georgian Law on Wild Fauna Protection came into effect on 1 September 1997. This law clearly defines the responsibilities of the State authorities, as 
well as civil obligations for the protection and conservation of wildlife (Anonymous 1996). It also caters for the protection of migratory birds, specifically excluding game species. Moreover, Georgia is signatory to the Convention on Biological Diversity (CBD) and the Convention on International Trade in Endangered Species (CITES). A strong lobby of hunters is objecting to the new hunting legislation. Awareness of new legislation and international conventions and agreements among the general public is poor. Throughout this study no law enforcement was encountered in the field. Eco-police are basically understaffed, feel incompetent and are without sufficient financial means. The police generally turn a blind eye, can even be part of the hunting community, or are too preoccupied in the lucrative business of traffic policing. Anarchy is widespread in this respect. Conservationists strive to effect positive change in environmental thinking and attitudes of decision makers and the general public. Their important work is unfortunately constrained in a weary society in socioeconomic crisis, with dogmatic forces holding the strings. Nevertheless there are glimmers of hope and scope for improvement. For instance, during our surveys we frequently entered into constructive dialogue with trappers and hunters, motivating the value and importance of protecting wildlife, the magnificence and symbolism of birds of prey, and illustrating the negative effects of their actions. Generally, the Georgian people are quite receptive to good arguments and education. Young hunters in particular were visibly ashamed after a discussion on the subject and admitted they did not know any better, but would like to change their ways and learn more about conservation problems. Revitalizing a sense of personal responsibility for the common good of Georgian society and the wise management of natural resources is part of the solution. Conservation thinking is actually entrenched in Georgian rural traditions and in culture, but is of low priority. In contrast to their western countrymen, hunters in eastern Georgia actually have a sense of respect and feeling of kinship for raptors, which they regard as kindred spirits that should not be killed, let alone consumed. The Adjarian Department of Environment until recently was only marginally aware of the problem, and expressed a concern and willingness to undertake action towards solving it. However they need staff who are competent and equipped to deal with the problem effectively. The President and several members of the Falconers' Association genuinely shared our concerns about the unacceptable mortality of migratory raptors. They would like to promote and develop a more disciplined and controlled sport, as was practised in the past, and approaching the standards of falconry in the West. They do not agree with the killing of raptors through trapping and hunting, and are willing to support conservation initiatives, such as the dissemination of educational materials (posters and booklets) and development of special activities (seminars, school projects, television programmes, etc.). It would be very useful to produce a "best-practice" handbook for falconry in Georgia, with information on raptors and other birds migrating in the area, their conservation status and needs. An explicit code of ethics based on internationally accepted standards in falconry and practice for the safekeeping (e.g. veterinary care) of raptors should be included. Raptor researchers, bird conservationists and falconers from the West are invited to contribute to such a document. 


\section{Acknowledgements}

Constructive input to this study was provided by Givi Chogovadze, Sophiko Akhobadze, Nelly Terdzishvili and Nana Skhiladze. Thank you Rob Bijlsma for providing additional comments on improvement.

\section{References}

Abuladze, A. (1994) Birds of Prey in Georgia in the 20th Century. In: Meyburg, B.-U. and R.D. Chancellor, eds. Raptor conservation today. World Working Group of Birds of Prey. London: Pica Press.

Abuladze, A. (1996) Lesser Spotted Eagle Aquila pomarina in Georgia. In: B.-U. Meyburg, and R.D. Chancellor, eds. Eagle studies. World Working Group of Birds of Prey. London: Pica Press.

Abuladze, A. (1997). Status and conservation problems of raptors in Caucasia. Newsletter World Working Group of Birds of Prey 26/27: 15-19.

Anonymous (1996) The status of biodiversity in Georgia: Country study report. United Nations Environment Programme, Georgian Ministry of Environment and Noah's Ark Center for the Recovery of Endangered Species.

Baha El Din, S.M. and Salama, W. (1991) The catching of birds in North Sinai, autumn 1990. Cambridge, UK: International Council for Bird Preservation (Study Report 45).

Chogovadze, G. (1998) Falconry in Georgia. Information Leaflet by the Section of Falconry, Batumi: Georgian Union of Hunters and Fishermen.

Fenech, N. (1992) Fatal flight: the Maltese obsession with killing birds. London: Quiller Press.

Fenech, N. (1997) Bird shooting and trapping on the Maltese Islands. PhD Thesis. University of Durham, Department of Geography, Durham, U.K.

Ghambarasvili, N. (1969) Georgian hunters guide book. Batumi: Georgian Union of Hunters and Fishermen.

Maanen, E. van, I. Goradze, R. Goradze and I. Matchutadze (2000) Wetlands of Kolkheti. Deventer, The Netherlands: Earth Holistics Report.

Magnin, G. (1986) An assessment of illegal shooting and catching of birds in Malta. Cambridge, U.K.: ICBP (Study Report 13).

Magnin, G. (1989) Falconry and hunting in Turkey during 1987. Cambridge, U.K.: ICBP (Study Report 34).

Magnin, G. (1991) Hunting and persecution of migratory birds in the Mediterranean region. Cambridge, U.K.: (Techn. Publ. 12: 63-75).

Robakidze, A. (1949) Hunting with sparrowhawks in Guria. Dissertation. Institute of History, Georgian Academy of Sciences, Tblisi.

ERWIN VAN MAANEN

Earth Holistics, Molenstraat 79, 7411 NR Deventer, The Netherlands

IRAKLI GORADZE and REZO GORADZE

Regional Activity Centre for Black Sea Biodiversity Conservation, 51 Rustaveli Street, 384500 Batumi, Georgia

\section{ALEXANDER GAVASHELISHVILI}

Georgian Centre for the Conservation of Wildlife, Ambrolaury Street 4/2, 380060 Tblisi, Georgia

Received 23 July 1999; revision accepted 16 January 1991 